\title{
Harpacticoid copepod colonization of coral fragments in a tropical reef lagoon (Zanzibar, Tanzania)
}

\author{
M. CALlENS ${ }^{1,4}$, H. GHEERARDYN ${ }^{2}$, S.G.M. NDARO $^{3}$, M. DE TROCH ${ }^{1}$ AND A. VANREUSEL ${ }^{1}$ \\ ${ }^{1}$ Marine Biology Section, Biology Department, Ghent University, Krijgslaan 281-S8, 9000 Ghent, Belgium, ${ }^{2}$ Royal Belgian \\ Institute of Natural Sciences, Vautierstraat 29, 1000 Brussels, Belgium, ${ }^{3}$ Department of Aquatic Environment and Conservation, \\ University of Dar Es Salaam, PO Box 35064, Dar Es Salaam, Tanzania, ${ }^{4}$ Aquatic Biology, K.U. Leuven—KULAK, E. Sabbelaan 53, \\ 8500 Kortrijk, Belgium
}

\begin{abstract}
Colonization experiments were conducted in a tropical lagoon (Zanzibar Island, off the coast of Tanzania) to investigate the temporal dynamics and mode of colonization of the harpacticoid copepods community on dead coral fragments. There was fast colonization of the coral fragments attaining a substantial diversity after only two days. The ability to colonize dead coral fragments is thought to be related to the morphology and life style of different harpacticoid species. Phytal taxa (e.g. Tisbidae) were fast colonizers, reaching high abundances during the initial colonization phase. Sediment-associated and eurytopic taxa (e.g. Ameiridae, Miraciidae and Ectinosomatidae) showed lower colonization rates and became the dominant group during the later colonization phase. Most species are able to colonize the coral fragments through the water column. However, colonization along the substrate surface is also considered to be an important colonization mode, especially for sediment-associated taxa, which showed lower colonization rates when migration through the sediment was hindered.
\end{abstract}

Keywords: dead coral substrates, harpacticoid copepods, community structure, colonization experiments, temporal dynamics, Indian Ocean

Submitted 14 March 2011; accepted 17 August 2011

\section{INTRDDUCTION}

Back-reef systems are tropical nearshore environments between the leeward-side of the reef-crest and mean high tide along the shore. They consist of an interconnected mosaic of diverse habitat types such as mangroves, seagrass meadows, patch reefs and the hard- or soft-bottom seafloor (Adams et al., 2006). Carbonate sediments in reef lagoons are derived from the erosion of corals and are intermixed with skeletal remains of other carbonate-bearing organisms (Alongi, 1989). Harpacticoid copepods are often the dominant meiofaunal taxon in these carbonate sediments (Alongi, 1989; Logan et al., 2008) and have a prominent role because of their numerical abundance (Hicks \& Coull, 1983), capacity to recycle nitrogen (Gray, 1985; Moriarty et al., 1985) and high bacterial ingestion rates (Montagna, 1984). Furthermore, they are an important food source for small, often juvenile demersal fish, carnivorous crustaceans and polychaetes (Giere, 2009) due to their epibenthic occurrence and high nutritional value (Coull, 1999). Several studies have investigated the meiofauna communities associated with carbonate reef sediments (e.g. Alongi, 1989; Ndaro \& Ólafsson 1999) and have mainly focused on the assemblages living on or within these soft substrates. Only two studies (Raes et al., 2007; Gheerardyn et al., 2008) have investigated the epimeiofauna living on hard coral substrates along the eastern African coast. Both nematode and

Corresponding author:

M. Callens

Email: callens.martijn@hotmail.com harpacticoid copepods communities differed on coral fragments compared to the surrounding sediment.

It is important to understand the dynamics of the harpacticoid community because they are a component of the many processes that operate in back-reef systems. Colonization experiments are of particular interest because they allow one to trace the establishment of the community from the very beginning, and to observe changes in its characteristics over time (Chertoprud et al., 2005). Experimental research on harpacticoid colonization has been conducted for a wide range of substrates, such as sediment depressions (Sun \& Fleeger, 1994), mesh collectors, bottle brushes and Hester-Dendy plates (Atilla \& Fleeger, 2000; Atilla et al., 2003), floating seaweed (Ólafsson et al., 2001), azoic sediments of different grain-size compositions (Chertoprud et al., 2005) and seagrass mimics (De Troch et al., 2005). In general, there is a fast colonization reaching high abundances and species diversity, even in less than a day, and sometimes exceeding the natural situation in less than a week (De Troch et al., 2005). Taxa absent from the background community have been recorded during colonization, implying that the total diversity of the colonization pool is broader than the actual observed local taxonomic diversity. This indicates the presence of a metacommunity, where a set of local communities are linked by migration flows and a common regional species pool (Chertoprud et al., 2005).

Little is known about which mode of colonization (i.e. along the substrate surface or through the water column) governs the formation of the community during colonization. Previous studies found that there is a highly mobile and 
diverse pool of harpacticoid copepods in the water column which can rapidly colonize newly available, free biotopes (Atilla et al., 2003; Chertoprud et al., 2005). Swimming abilities and passive or active emergence in the water column are known to be species-specific among sediment-dwelling and phytal meiofauna (Walters \& Bell, 1994). For example, Sun \& Fleeger (1994) found that phytal and epibenthic species were generally fast colonizers while interstitial and burrowing species appeared later during colonization. These differences in behaviour may account for the variation in colonization abilities of different species (Atilla et al., 2003).

The purpose of this study is to investigate the temporal dynamics of the harpacticoid community during colonization of dead coral fragments. Further, the contribution of the different colonization modes (through the sediment or via the water column), to the formation of the community will be assessed.

\section{MATERIALS AND METHDDS}

\section{Description of study area and experimental setup}

The study area is located in front of Fumba $\left(6^{\circ} 19^{\prime} \mathrm{S} 39^{\circ} 16^{\prime} \mathrm{E}\right)$ (Figure 1), a village on the south-western coast of Zanzibar Island (Tanzania, western Indian Ocean) at the tip of a small peninsula. This area is bordered by Zanzibar Channel to the west and Menai Bay to the east. The experimental area consisted of bare sediments with dead coral fragments and sparsely distributed small patches of living coral. The sediment was mainly composed of medium $(20.2 \% \pm 3.5 \%)$, coarse $(45 \% \pm 2.9 \%)$ and very coarse sand $(25.3 \% \pm 5.5 \%)$ with low silt, clay and fine sand content. The surrounding area consisted of bare sediments and large seagrass fields, of the genera Zostera, Halophila and Halodule more close to the beach and Thalassia, Cymodocea, Thalassodendron and Syringodium away from the beach. The experimental area was located at approximately $10 \mathrm{~m}$ from a Thalassia seagrass bed, was protected by a rocky outcrop (which was inundated only at high tide), and was connected with the open sea by a slightly deeper, narrow channel.

All 16 meiofauna samples were collected subtidally, at a distance of approximately $1000 \mathrm{~m}$ from the high-tide line. The depth in this area varied between $0.5 \mathrm{~m}$ and $4.5 \mathrm{~m}$, depending on the tide. First, dead coral fragments of comparable complexity were collected at the site of the experiment. Meiofauna samples were collected from two coral fragments to characterize the natural community. All coral fragments were defaunated by rinsing thoroughly with tap water and drying for at least 24 hours. Coral fragments were then placed in two types of PVC-cores. The open-type core consisted of an open PVC-tube (10 cm high, $20 \mathrm{~cm}$ inner diameter) (Figure 2a). The closed-type core had the same structure as the open-type except that a bottom was present in the centre of the tube (Figure $2 \mathrm{~b}$ ). These cores were inserted about $5 \mathrm{~cm}$ in the sediment and were anchored with 3 metal hooks. The cores and coral fragments remained inundated during low spring tide.

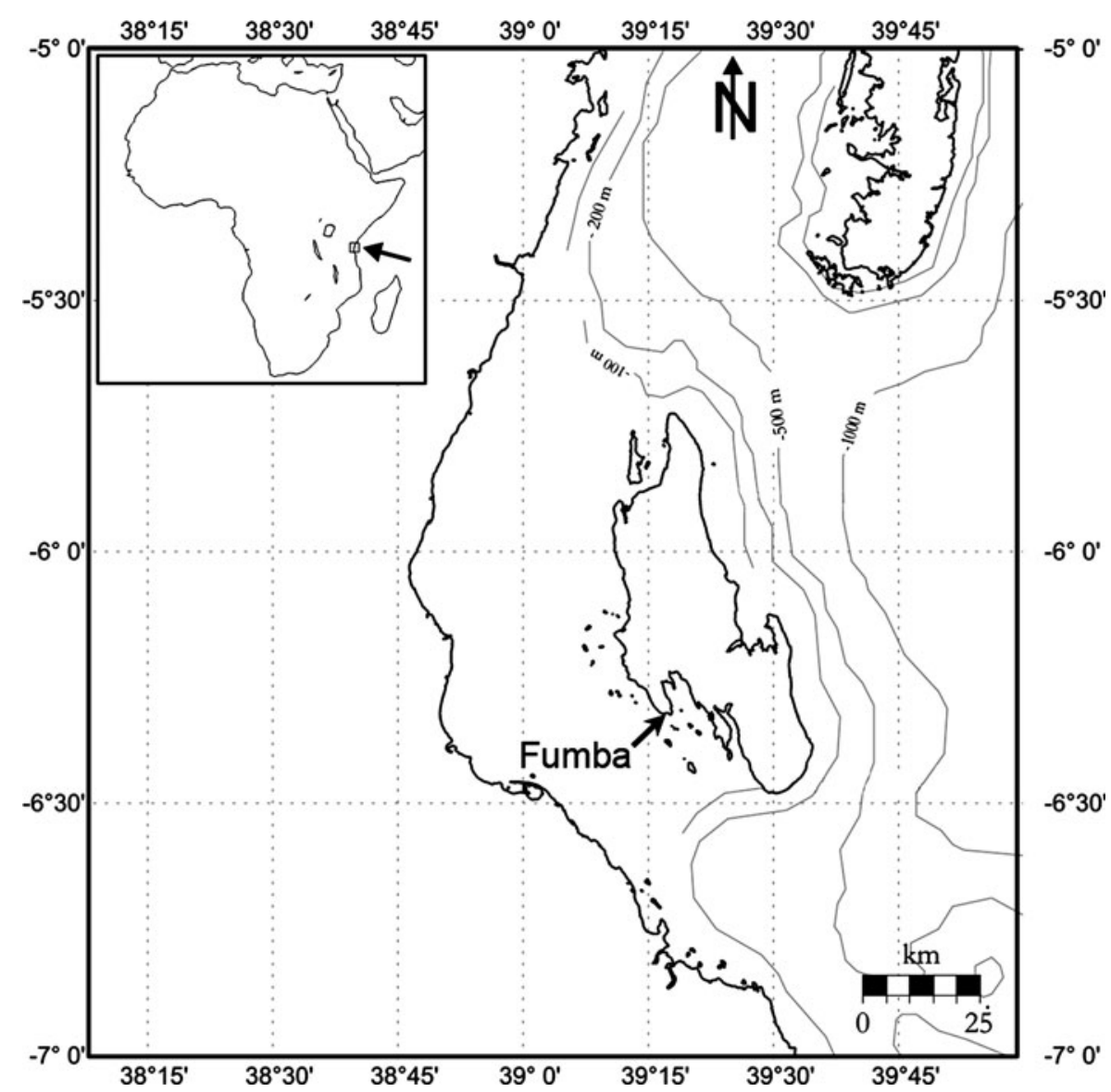

Fig. 1. Map of the study area indicating the sampling site. The northernmost island is Pemba, the southernmost Unguja (Zanzibar). 

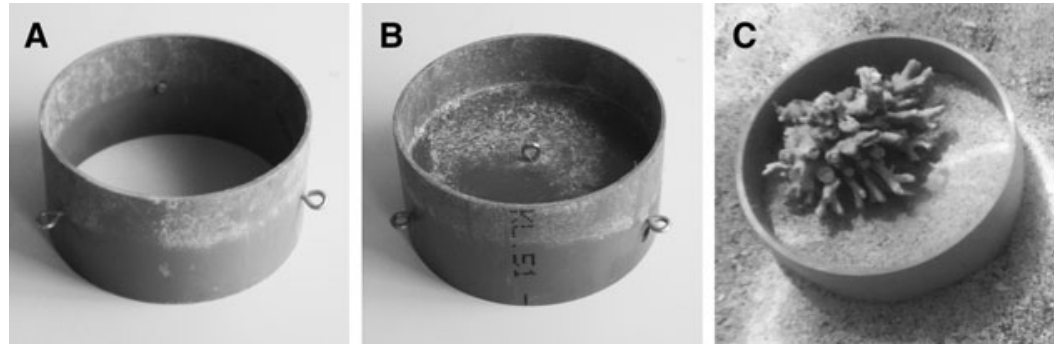

Fig. 2. PVC-cores used in the colonization experiment: (A) open-type PVC core; (B) closed-type PVC core; (C) in situ photograph during the experiment of a coral fragment inside an open-type PVC core.

To investigate whether colonization of coral fragments occurs through the sediment or the water column, two different treatments were used: open and closed. The open treatment consisted of a coral fragment placed in an open-type PVC core in order to keep direct contact between the coral fragment and both the underlying sediment and the water column. In the closed treatment, a coral fragment was placed in a closed-type PVC core to prevent contact between coral fragment and the underlying sediment, while direct contact with the water column remained.

Both treatments were replicated twice and replicates were placed $3.30 \mathrm{~m}$ to $4.60 \mathrm{~m}$ apart from each other. Each replicate consisted of an open and a closed core which were placed $1 \mathrm{~m}$ from each other. To investigate the effect of time on colonization, meiofauna was sampled at three different time intervals, i.e. 2, 6 and 14 days after the start of the experiment.

Sediment samples were collected by inserting a $10 \mathrm{~cm}^{2}$ core to characterize the community in the upper layer $(0-1 \mathrm{~cm})$ of the surrounding sediment.

\section{Sample processing}

Samples were taken during low tide. The entire coral fragment was gently placed in a plastic bag, to minimize disturbance, and sealed with rubber bands to transport to the shore for further treatment. Subsequently, $\mathrm{MgCl}_{2}$ was added to the bag to stun the meiofauna. After 15 minutes, the coral fragment and contents of the bag were rinsed thoroughly with filtered seawater over a $1 \mathrm{~mm}$ and $32 \mu \mathrm{m}$ sieve to separate the macro- and meiofauna, respectively. All samples retained on the sieves were fixed in $4 \%$ buffered formalin. Meiofaunal organisms were further extracted from the sediment particles by density gradient centrifugation using Ludox $\mathrm{HS}_{40}$ o floating medium with a specific density of 1.18 (Heip et al., 1985). Meiofauna was stained with rose Bengal. From each sample, 200 copepods (or all copepods when fewer than 200 individuals were present) were randomly picked out under a Wild M5 binocular microscope and mounted on glycerin slides.

Adult copepods were identified to genus level using Lang (1948, 1965), Huys et al. (1996) and Boxshall \& Halsey (2004). Systematics and nomenclature follow Wells (2007) and Huys (2009). Genera were classified according to body shape following Coull (1977).

\section{Statistics}

A non-metric multidimensional scaling, two-dimensional plot (MDS) was produced, using the Bray-Curtis similarity index. For each sample, data were standardized to relative abundances and root-transformed prior to analysis. The significance of the MDS was tested using a one-way analysis of similarities (ANOSIM) and a two-way crossed ANOSIM. Similarity of percentages (SIMPER) was used to identify the taxa contributing to the differences found in the ordination analysis. All multivariate tests were performed using PRIMER 6.1.12 software (Clarke \& Gorley, 2006).

Non-parametric analysis for comparing multiple independent sample groups was performed on untransformed data using a Kruskal-Wallis analysis of variance (ANOVA). A Mann-Whitney $U$-test was employed for comparing two independent sample groups. These analyses were performed using STATISTICA7 software.

\section{RESULTS}

A total of 3030 copepods were identified, of which $91.6 \%$ belonged to the order Harpacticoida, $8.4 \%$ to the order Cyclopoida and only one individual to the order Siphonostomatoida.

\section{Relative abundances of copepodites}

In total, $69.5 \%$ of all harpacticoids were copepodites. A significant difference in copepodite abundance on coral fragments was found between different days (Kruskal-Wallis ANOVA, $P=0.02)$. The relative abundance of copepodites in the natural situation was $66.6 \% \pm 3.9 \%$ (Figure 3 ). The highest percentages of copepodites were recorded on days 2 and 6 of the colonization experiment. Here, abundances were comparable on both sampling occasions, with no discernible differences between treatments (Mann-Whitney $U$-test, $P=$ 1.00). On day 14 , both treatments had a lower relative abundance of copepodites than in the natural situation, with $62.8 \% \pm 0.4 \%$ in the open and $56.5 \% \pm 1.9 \%$ in the closed treatment. The lowest abundance of copepodites was found in the sediment, where they only represented $34.1 \% \pm 1.7 \%$ of the harpacticoid community.

\section{Harpacticoid assemblages}

Over the complete dataset, $30.5 \%$ of the 2776 harpacticoid individuals were adults. These belonged to 16 different families and 45 different genera (see Appendix). Overall, the families Ectinosomatidae Sars, 1903 (22.4\%), Tisbidae Stebbing, 1910 (21.7\%) and Ameiridae Boeck, 1865 (15.6\%) were most abundant. The most abundant genera were Ectinosoma Boeck, 1965 (21.5\%), Tisbe Lilljeborg, 1853 (19.4\%) and Ameira 


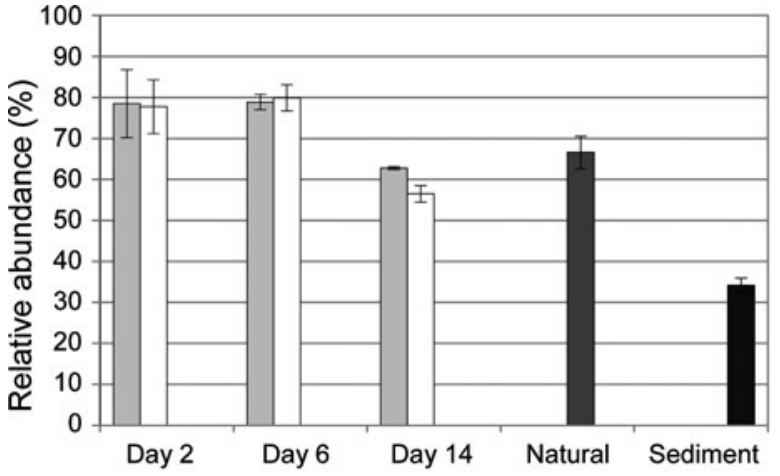

$\square$ Open treatment $\square$ Closed treatment $\square$ Natural $\square$ Sediment

Fig. 3. Relative abundances $( \pm S D)$ of copepodites over different sample times and treatments.

Boeck, 1865 (12.5\%). The family Miraciidae Dana, 1846 showed the highest generic diversity, with a total of 8 genera. An overview of the most abundant families and genera over different samples is given in Figure 4 and Table 1.

\section{BACKGROUND COMMUNITIES}

Assemblage on coral fragments

In total, 11 different families including 25 genera were found on coral fragments in the natural situation. The assemblage on the coral fragments (Table 1 ) was dominated by the family Ameiridae (mainly Ameira), followed by Ectinosomatidae (mainly Ectinosoma) and Miraciidae. Together, these three families accounted for $60.4 \% \pm 4.2 \%$ of the natural harpacticoid community. Tisbe had a slightly higher abundance than Amphiascus Sars, 1905, and these were both the dominant genera in the families Tisbidae and Miraciidae, respectively. However, due to a higher number of individuals in other genera, the family Miraciidae comprised a larger percentage of the natural community than Tisbidae.

Assemblage in the sediment

The harpacticoid community in the sediment samples had a significantly different composition than the one on coral fragments (one-way ANOSIM: global $\mathrm{R}=0.929, P=0.008$ ). Furthermore, there was a strong difference between the two sediment replicates. In total, 11 different families including 16 genera were found in the sediment. Overall, the sediment was dominated by Ameiridae (Ameira and Ameiropsis Sars, 1907), followed by Tetragonicipitidae Lang, 1944 (Diagoniceps Willey, 1930 and Phyllopodopsyllus T. Scott, 1906), Miraciidae (Amphiascus and Robertguerneya Lang, 1948) and Canuellidae Lang, 1944 (only Brianola Monard, 1927). However, Diagoniceps was only found in one replicate and was also the dominant genus here.

\section{COLONIZATION EXPERIMENT}

Day 2

On day 2 of the colonization experiment, Tisbidae (Tisbe and Scutellidium Claus, 1866) dominated both the open $(62.6 \% \pm 14.4 \%)$ and closed $(55.9 \% \pm 15.1 \%)$ treatments. Ameiridae (mainly Ameira) was the second most abundant family in the open treatment, followed by Ectinosomatidae (mainly Ectinosoma). In the closed treatment, Ameiridae had a much lower abundance than Ectinosomatidae, which was the second most abundant family. The family Dactylopusiidae Lang, 1963 (mainly Diarthrodes Thomson, 1883) was abundant in both the open and closed treatments. After two days of colonization, the open and closed treatments had a total of 8 (16) and 9 (11) families (genera), respectively. The family Parastenheliidae Lang, 1936 was only present in the open treatment samples, while the families

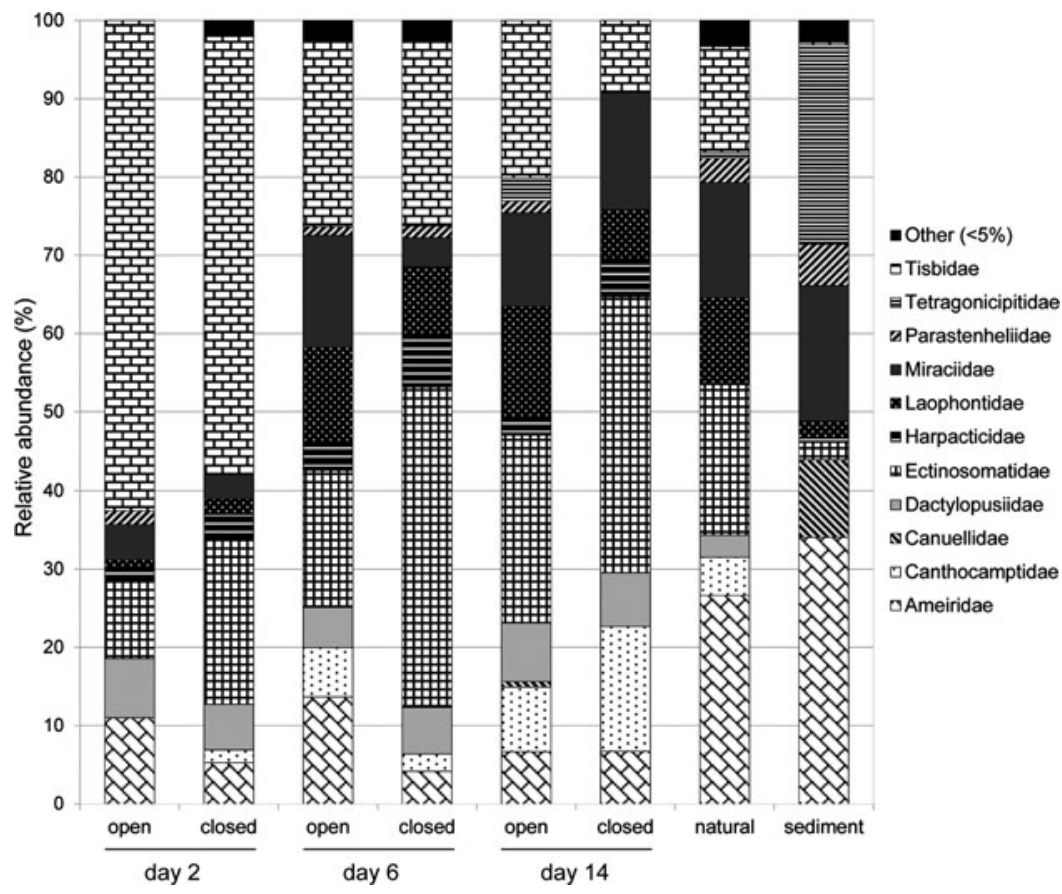

Fig. 4. Relative abundances of the dominant harpacticoid families in: days 2, 6 and 14 during the experiment for both the open and closed treatments; the natural community on coral fragments; and the community in the sediment. 
Table 1. Relative abundances (\%) \pm standard deviation of harpacticoid genera after different colonization times and treatments. Only genera with a relative abundance $>2 \%$ in at least one sample are given.

\begin{tabular}{|c|c|c|c|c|c|c|c|c|c|c|c|c|c|c|c|c|c|}
\hline \multirow[t]{3}{*}{ Family } & \multirow[t]{3}{*}{ Genus } & \multicolumn{4}{|c|}{ Day 2} & \multicolumn{4}{|c|}{ Day 6} & \multicolumn{4}{|c|}{ Day 14} & \multicolumn{2}{|c|}{ Natural } & \multicolumn{2}{|c|}{ Sediment } \\
\hline & & \multicolumn{2}{|c|}{ Open } & \multicolumn{2}{|c|}{ Closed } & \multicolumn{2}{|c|}{ Open } & \multicolumn{2}{|c|}{ Closed } & \multicolumn{2}{|c|}{ Open } & \multicolumn{2}{|c|}{ Closed } & \multirow[t]{2}{*}{$\%$} & \multirow[t]{2}{*}{$\pm \mathrm{SD}$} & \multirow[t]{2}{*}{$\%$} & \multirow[t]{2}{*}{$\pm \mathrm{SD}$} \\
\hline & & $\%$ & $\pm \mathrm{SD}$ & $\%$ & \pm SD & $\%$ & $\pm \mathrm{SD}$ & $\%$ & $\pm \mathrm{SD}$ & $\%$ & $\pm \mathrm{SD}$ & $\%$ & $\pm \mathrm{SD}$ & & & & \\
\hline \multirow[t]{3}{*}{ Ameiridae } & Ameira & 10.1 & 2.4 & 5.3 & 1.2 & 9.8 & 1.0 & & & 5.2 & 3.7 & 6.7 & 1.4 & 20.7 & 2.2 & 28.5 & 16.5 \\
\hline & Ameiropsis & 0.9 & 0.9 & & & 3.8 & 1.6 & 4.1 & 1.9 & 1.5 & & & & 1.0 & 1.0 & 5.5 & 5.5 \\
\hline & Psyllocamptus & & & & & & & & & & & & & 4.1 & 2.0 & & \\
\hline Canthocamptidae & Mesochra & & & 1.6 & 1.6 & 4.9 & 0.5 & 2.2 & 2.2 & 8.2 & 0.9 & 15.4 & 0.9 & 4.9 & 2.8 & & \\
\hline Canuellidae & Brianola & & & & & & & & & & & & & & & 9.8 & 2.2 \\
\hline \multirow[t]{3}{*}{ Dactylopusiidae } & Dactylopusia & 2.8 & 1.0 & 1.0 & 1.0 & 5.2 & 2.9 & 6.0 & 2.9 & 4.5 & 0.1 & 2.5 & 0.2 & 2.1 & 2.1 & & \\
\hline & Diarthrodes & 4.7 & 3.0 & 4.8 & 4.8 & & & & & 1.5 & & 1.9 & 0.7 & & & & \\
\hline & Paradactylopodia & & & & & & & & & 1.5 & 1.5 & 2.5 & 0.2 & 0.8 & 0.8 & & \\
\hline Ectinosomatidae & Ectinosoma & 9.1 & 5.2 & 21.2 & 11.5 & 17.5 & 4.1 & 39.3 & 2.9 & 23.9 & 0.4 & 35.2 & 0.3 & 15.0 & 0.4 & 1.6 & 1.6 \\
\hline Harpacticidae & Harpacticus & 1.8 & 1.8 & 3.1 & 3.1 & 3.6 & 0.9 & 6.7 & 6.7 & 2.3 & 2.3 & 3.7 & 0.2 & & & & \\
\hline \multirow[t]{2}{*}{ Laophontidae } & Laophonte & & & & & 3.3 & 3.3 & & & 0.7 & 0.7 & 0.6 & 0.6 & 4.9 & 2.8 & 2.2 & 2.2 \\
\hline & Paralaophonte & 0.9 & 0.9 & 2.0 & 2.0 & 7.6 & 3.2 & 7.2 & 4.9 & 13.5 & 1.7 & 5.6 & 1.0 & 5.2 & 1.0 & & \\
\hline Longipediidae & Longipedia & & & & & & & & & & & & & 2.3 & 2.3 & & \\
\hline \multirow[t]{4}{*}{ Miraciidae } & Amphiascoides & 0.9 & 0.9 & & & 1.1 & 1.1 & & & 4.5 & 1.4 & 2.5 & 0.2 & 1.8 & 0.3 & & \\
\hline & Amphiascus & 0.9 & 0.9 & 3.1 & 3.1 & 7.8 & 7.8 & 2.2 & 2.2 & 6.0 & 3.1 & 9.5 & 3.7 & 10.3 & 2.0 & 7.6 & 4.4 \\
\hline & Robertgurneya & 1.8 & 1.8 & & & 1.4 & 1.4 & & & 0.7 & 0.7 & 0.6 & 0.6 & 1.0 & 1.0 & 9.6 & 6.4 \\
\hline & Schizopera & 0.9 & 0.9 & & & 2.7 & 2.7 & 1.5 & 1.5 & & & & & & & & \\
\hline Paramesochridae & Emertonia & & & & & & & & & & & & & & & 2.0 & 2.0 \\
\hline \multirow[t]{2}{*}{ Parastenheliidae } & Karllangia & 0.9 & 0.9 & & & 1.1 & 1.1 & & & 0.7 & 0.7 & & & & & 1.6 & 1.6 \\
\hline & Parastenhelia & 0.9 & 0.9 & & & & & 1.5 & 1.5 & 0.7 & 0.7 & & & 3.1 & 3.1 & 3.6 & 0.4 \\
\hline Tegastidae & Tegastes & & & 2.0 & 2.0 & 1.4 & 1.4 & 2.6 & 0.4 & & & & & & & & \\
\hline \multirow[t]{2}{*}{ Tetragonicipitidae } & Diagoniceps & & & & & & & & & & & & & & & 16.0 & 16.0 \\
\hline & Phyllopodopsyllus & & & & & & & & & 3.0 & & & & 0.8 & 0.8 & 9.5 & 1.5 \\
\hline \multirow[t]{2}{*}{ Tisbidae } & Scutellidium & 7.4 & 0.3 & 8.8 & 5.5 & 1.1 & 1.1 & & & 2.3 & 2.3 & & & 2.1 & 2.1 & & \\
\hline & Tisbe & 55.2 & 14.1 & 47.1 & 20.6 & 22.6 & 6.3 & 23.6 & 3.6 & 17.8 & 4.2 & 9.2 & 1.3 & 11.4 & 5.3 & 0.5 & 0.5 \\
\hline
\end{tabular}


Canthocamptidae Brady, 1880 and Tegastidae Sars, 1904 were only present in the closed treatment samples.

\section{Day 6}

After six days of colonization, the total number of families (genera) in the open treatment was 11 (20), while in the closed treatment this was 10 (13). Here, the same families were found in the open and closed treatment, except for the Paramesochridae Lang, 1944 (Apodopsyllus Huys, 2009) which was only present in the open treatment. Although Tisbidae showed a strong decline in comparison to day 2, this was still the dominant family in the open treatment $(23.7 \% \pm 7.5 \%)$. In the closed treatment Ectinosomatidae $(40.8 \% \pm 1.4 \%)$ (mainly Ectinosoma) dominated the harpacticoid community. However, the relative abundance of Tisbidae (Tisbe) in the closed treatment was comparable to the open treatment, while the percentage of Ectinosomatidae (Ectinosoma) in the open $(17.5 \% \pm 4.1 \%)$ treatment was substantially lower than in the closed treatment. In the open treatment, the families Ameiridae (Ameira and Ameiropsis) and Miraciidae (mainly Amphiascus) showed higher abundances than the closed treatment. The family Laophontidae T. Scott, 1905 (mainly Paralaophonte Lang, 1948) was abundant in both the open and closed treatments, with the open treatment having a slightly higher percentage of laophontids than the closed treatment.

\section{Day 14}

After 14 days of colonization, the open treatment had a greater diversity ( 11 families and 20 genera) than the closed treatment (8 families and 17 genera). Here, the families Canuellidae, Parastenheliidae and Tetragonicipitidae were only found in the open treatment. On day 14, Ectinosomatidae (only Ectinosoma) had the highest relative abundance in both the open $(23.9 \% \pm 0.4 \%)$ and closed $(35.2 \% \pm 0.3 \%)$ treatments. In comparison to day 6, abundances of Ectinosoma were slightly lower in the closed treatment, while in the open treatment there was an increase of this genus. There was a further decline in the Tisbidae and this family (mainly Tisbe) made up a larger part of the community in the open treatment than in the closed treatment. The family Laophontidae (mainly Paralaophonte) showed also a marked difference between treatments, having a higher abundance in the open treatment. The families Canthocamptidae (mainly Mesochra Boeck, 1865) and Miraciidae (mainly Amphiascoides Nicholls, 1941 and Amphiascus) showed comparable abundances in the closed treatment and made up a larger part of the community than in the open treatment. Dactylopusiidae (Dactylopusia Norman, 1903 and Paradactylopodia Lang, 1944, Diarthrodes) and Ameiridae (Ameira and Ameiropsis) showed similar abundances in both the open and the closed treatments.

\section{FUNCTIONAL COMPOSITION BASED ON DIFFERENT BODY TYPES}

Classification according to body type (following Coull, 1977) shows that the natural community is dominated by the fusiform prehensile body type, followed by the fusiform and the fusiform depressed body type (Figure 5). On day 2 of the colonization experiment the fusiform depressed body type (mainly due to the presence of Tisbe) was the most abundant in both treatments. Other abundant body types were fusiform and fusiform prehensile. On day 6 , the fusiform prehensile body type was dominant in the open treatment while in the closed treatment it was the fusiform (mainly Ectinosoma) body type. The fusiform depressed body type made up an equal part in both treatments. On day 14, both treatments were dominated by the fusiform prehensile body type which had comparable abundances in both the open and closed treatment. The fusiform compressed body type was present in all coral samples and the compressed body type was found in three coral samples, while both these body types were absent from the sediment. The sediment was dominated by the fusiform prehensile body type followed by the fusiform (non-prehensile) and with low abundances of the vermiform, fusiform depressed and fusiform body types.

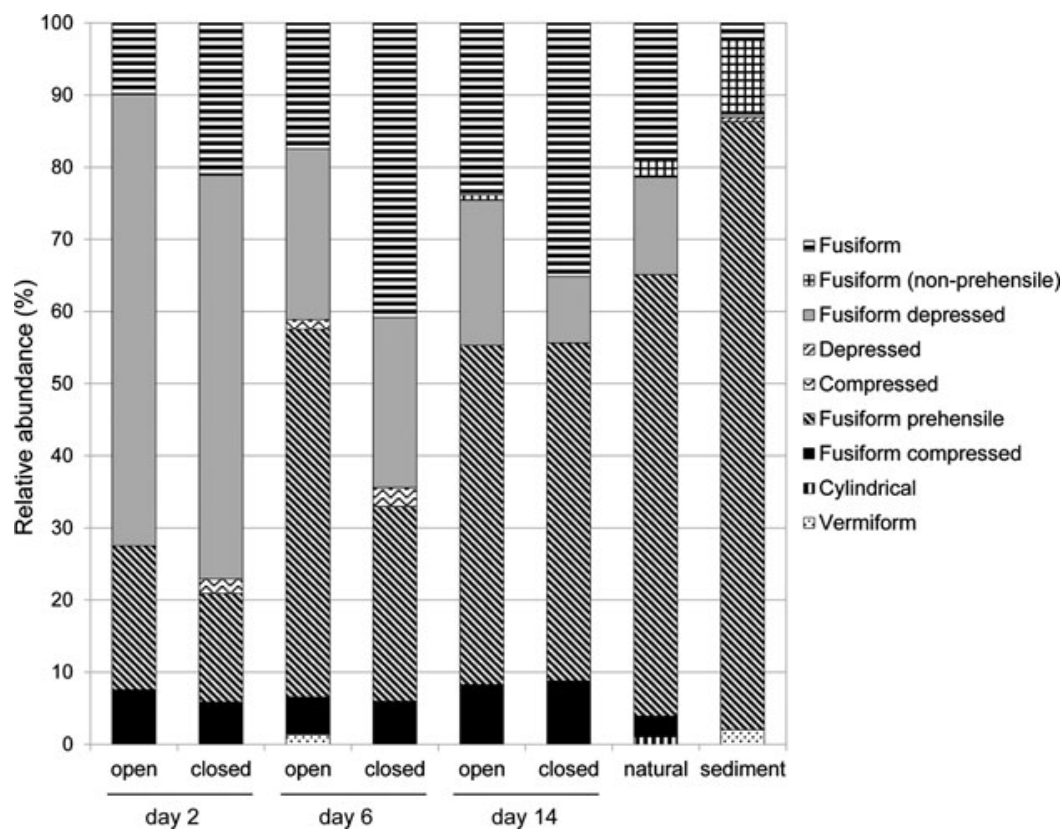

Fig. 5. Relative abundances of different body types over different samples. 


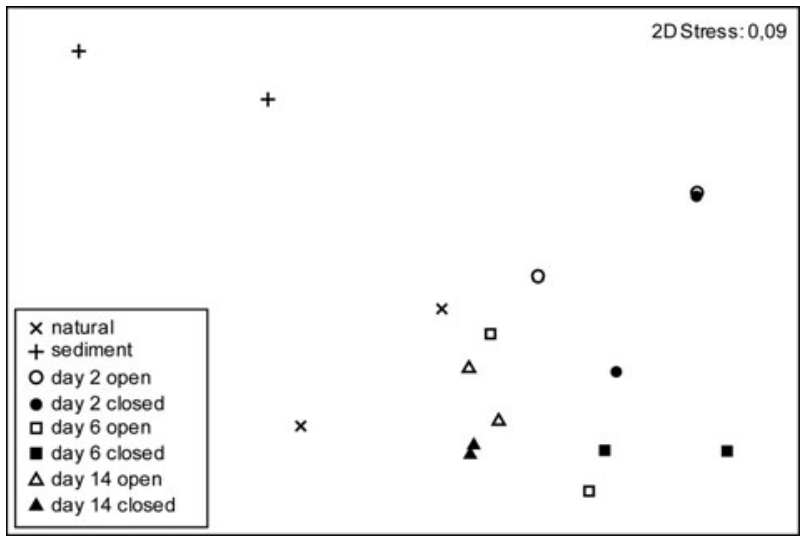

Fig. 6. Multidimensional scaling, two-dimensional ordination plot of all samples. Stress value is 0.09 .

\section{Community analysis}

In the MDS-plot (stress: 0.09) sediment samples clearly separated from the coral samples (Figure 6). Within the coral samples it was hard to delineate clear groupings. Overall, samples taken on day 14 cluster closely together, this indicates that there was less variability in community structure after a longer colonization time. Samples taken on day 2 and day 6 showed a high degree of scattering. An MDS-plot at the family level or of morphological types (not shown) produced the same overall plot with a clear separation of the sediment samples from the coral fragments, but no clear delineated groups within the coral samples.

A two-way crossed ANOSIM for the experimental coral samples indicated a significant difference in community composition between different days (global $\mathrm{R}=0.389, P=0.018$ ), but absence of a significant difference between the open- and closed treatments (global $\mathrm{R}=-0.083, P=0.63$ ). A pairwise analysis did not indicate any significant differences between different days. There was a significant difference in the harpacticoid community between the coral fragments and the sediment, as indicated by a one-way ANOSIM (global $\mathrm{R}=$ 0.929, $P=0.008$ ). A one-way ANOSIM for different days of the colonization experiment (without taking into account the different treatments) and the natural situation did not indicate any significant difference in community composition between them (global $\mathrm{R}=0.545, P=0.1$ ).

A two-way SIMPER-analysis was conducted on the experimental coral samples (both open and closed treatments for days 2, 6 and 14) (Table 2). Dissimilarity between open and closed treatments indicated only a small difference between the two groups. Ectinosoma had the greatest contribution to the dissimilarity between the two treatments and was thus most affected by the closed bottom. Between day 2 and day 6 the contribution of only 3 genera (Tisbe, Ectinosoma and Scutellidium) can explain half of the dissimilarity. Between day 6 and day 14, Tisbe (14.0\%) and Mesochra (10.4\%) were the greatest contributors to dissimilarity. Tisbe (34.1\%) was also the main contributor to dissimilarity between day 2 and day 14, followed by Ectinosoma (13.1\%) and Mesochra (10\%). A one-way SIMPER-analysis was conducted between the coral samples (both experimental and the natural) and the sediment samples. Dissimilarity between the coral- and sediment samples indicates a substantial difference between them. Tisbe (10.0\%) had the greatest contribution to the
Table 2. Similarity within and dissimilarity between different treatments and colonization times. A two-way similarity of percentages (SIMPER)-analysis was used for: open versus closed; day 2 versus day 6; day 2 versus day 14; and day 6 versus day 14. A one-way SIMPER-analysis was used for natural versus sediment.

\begin{tabular}{llll}
\hline & Similarity (\%) & \multicolumn{2}{c}{ Dissimilarity (\%) } \\
\hline Open & 63.9 & Open - closed & 37.6 \\
Closed & 65.1 & Day 2-day 6 & 49.3 \\
Day 2 & 53.4 & Day 2-day 14 & 55.2 \\
Day 6 & 60.3 & Day 6-day 14 & 39.5 \\
Day 14 & 79.9 & Natural-sediment & 75.3 \\
Natural & 54.9 & & \\
Sediment & 49.7 & & \\
\hline
\end{tabular}

dissimilarity between the coral samples and the sediment, followed by Ectinosoma (8.3\%) and Brianola (7.0\%).

\section{DISCUSSION}

\section{Characterization of the background community}

The natural community on dead coral fragments at the experimental site (near Fumba) was found to be an assemblage composed of phytal (e.g. Tisbe, Scutellidium and Dactylopusia), eurytopic (e.g. Ectinosoma) and sediment-associated (e.g Ameira and Amphiascus) taxa (see Noodt (1971) for classification). This was comparable to the assemblages reported for coral fragments along the eastern coast of Zanzibar (Gheerardyn et al., 2008). Although almost all recorded taxa were the same, a slightly different abundance pattern was found. Meiofaunal communities have been found to be variable both between and within reef zones (Ndaro \& Ólafsson, 1999; Armenteros et al., 2010). These differences can be caused by several factors, such as food availability (algal biomass), predation pressure and substrate complexity (Klumpp et al., 1988).

The harpacticoid community on coral fragments differed significantly from those in the surrounding sediment because of: (a) high relative abundances of phytal (e.g. Tisbe) and eurytopic (e.g. Ectinosoma) taxa on the coral fragments; and (b) the presence of certain sediment-associated taxa in the sediment (e.g. Brianola, Diagoniceps and Phyllopodopsyllus) which were absent or occurred with very low relative abundances on the coral fragments. These results concur with the studies by Atilla et al. (2003) and Gheerardyn et al. (2008), in which high relative abundances of typical phytal and eurytopic taxa were found on hard substrates and certain other taxa were restricted to the sediment.

Within the sediment samples, there was a large difference in composition between the two replicates. This was mainly due to the dominance of Diagoniceps in one replicate, while this genus was absent from the other. Hicks \& Coull (1983) found that carbonate sediment assemblages can show a very patchy distribution. They found a coarse shell-gravel patch to be dominated by Phyllopodopsyllus (also a member of the Tetragonicipitidae) while at a site (sampled monthly) at a distance of $200 \mathrm{~m}$, they found only 2 specimens of this genus over a period of 10 years. A similar pattern was found by Gheerardyn et al. (2008), where Diagoniceps dominated the sediment (containing a large coarse sand fraction) at 
Makunduchi, while it occurred only with low abundances at Matemwe.

\section{Temporal dynamics of the harpacticoid community during colonization}

Most studies observe a rapid colonization by meiofauna, with total abundances reaching, and even exceeding, the natural situation early during colonization and establishing a highly diverse community even within a few hours (e.g. Chertoprud et al., 2005; De Troch et al., 2005). There was already a substantial diversity of harpacticoid genera on the coral fragments during the early colonization phase. Copepods are generally fast colonizers due to their high motility and ability to actively emerge from the substrate, and are mostly the first to colonize a newly available habitat (Palmer, 1988). However, De Troch et al. (2005) found that nematodes were the dominant group during early colonization stages on artificial seagrasses and hypothesized that arrival of copepods was dependent on the development of a biofilm on the substrate.

The ability to rapidly colonize free space seems to be species-specific, with the sequence of colonization succession related to the life style and motility of the different harpacticoid species. Sun \& Fleeger (1994) found that phytal and epibenthic species (e.g. Coullana sp. Por, 1984 and Halicyclops coulli Herbst, 1977) were generally the first colonizers, while interstitial and burrowing species (e.g. Nannopus palustris Brady, 1880) appeared later during colonization. In the present experiment, phytal taxa were found to be dominant on day 2 of the colonization experiment, with members of the genus Tisbe being the fastest colonizers, constituting approximately half of the community. Several behavioural and morphological aspects are related to their ability to quickly colonize these newly available habitats. Members of this genus live near the surface of the sediment or on macroalgae (Huys et al., 1996), which makes them more susceptible to suspension in the water column because of the more exposed nature of these habitats (Hicks, 1992). Walters \& Bell (1994) also observed Tisbe furcata Baird, 1937 actively entering the water column through emergence. The combination of both passive erosion and active emergence will enable a high number of individuals to enter the water column, which will increase the availability of recruits for colonization via the water column. They are also known to be good swimmers, which is reflected by their cyclopoidean appearance (Noodt, 1971), and several studies already suggested that phytal meiofauna have good dispersing capabilities with the ability to travel through the water column for relatively long distances (Palmer \& Gust, 1985; Kurdizel \& Bell, 1992). Palmer (1988) assumes that active habitat selection can be expected in these strong swimmers and this could give them the ability to rapidly colonize free space. Other phytal taxa found on these coral fragments (i.e. Dactylopusia, Harpacticus Milne-Edwards, 1840, Tisbe, Scutellidium and Diarthrodes) have richly setose legs which are well adapted to swimming (Giere, 2009) and a prehensile first pair of pereiopods for clinging to the substrate. These morphological adaptations probably allow them to quickly colonize a new habitat by attaching onto it. The overall relative abundance of phytal genera decreased over the course of the colonization experiment and they were no longer dominant after six days of colonization. However, certain families classified as phytal (i.e. Harpacticidae Dana, 1846 and Dactylopusiidae) were found in higher relative abundances on later days. This may reflect their inferior colonization capabilities in comparison to, for example, Tisbidae.

Eurytopic genera, of which Ectinosoma was the most abundant representative, occur in most marine habitats (sand, mud and phytal) and appear to be 'jacks-of-all-habitats' (De Troch et al., 2005). On day 2 , they were already found in high relative abundances. Furthermore, on day 6 of the colonization experiment Ectinosoma had the highest relative abundance in the closed treatment, and there was a substantial increase in the open treatment. After 14 days of colonization Ectinosoma was the dominant genus in both treatments. Ectinosomatids are known to be good swimmers (Noodt, 1971) and active emergence from the sediment has also been recorded for this group (Walters \& Bell, 1994; Thistle \& Sedlacek, 2004). Furthermore, they are found in a wide array of benthic habitats (e.g. muddy and sandy sediments, and macroalgae) (Huys et al., 1996). As the coral fragments were cleaned before the colonization experiment, all the sediment was removed from between the coral branches. During the experiment, sediment accumulated between the coral branches, creating different microhabitats on the coral fragments. In addition to coral branches, which might be a suitable substratum for true epibenthic or phytal harpacticoids, the accumulation of sediment can provide a microhabitat for sediment-dwellers. As ectinosomatids are found in both sandy sediments and in phytal habitats (Huys et al., 1996), they are likely to be found in both microhabitats provided by these coral fragments. The greater relative abundance of ectinosomatids during later colonization stages can thus be explained by their ability to occupy different microhabitats, while their lower abundances during early colonization are probably due to their inferior colonization capabilities in comparison to phytal taxa.

Sediment-associated harpacticoids were mostly represented by fusiform prehensile forms (e.g. Ameira, Amphiascus, Mesochra and Paralaophonte), which are good swimmers that live on sand and soft bottoms (Noodt, 1971). Other body types such as vermiform or cylindrical, which are mostly associated with an interstitial and burrowing lifestyle, were rarely found on the coral fragments. The relative abundance of sediment-associated harpacticoids increased during the colonization experiment. Although none of the genera of this group becomes dominant, the group as a whole (represented mainly by fusiform prehensile forms) dominates the harpacticoid community after 14 days of colonization. Ameira is the fastest sediment-associated colonizer; this genus was also found to be dominant in the natural situation and in one sediment replicate. The high relative abundance of Ameira in the surrounding environment can be an explanation for the fast colonization by this genus. On day 2 of the colonization experiment, the relative abundance of the families Miraciidae, Canthocamptidae and Laophontidae was low, while on day 6 and day 14 they already made up a substantial part of the harpacticoid community. It is possible that these sediment-associated taxa have slower dispersal rates, which causes them to arrive later during colonization. Also, the amount of sediment retained between the coral branches increases with time (the coral acts as a 'sediment trap'), which provides more potential habitats for sediment-associated taxa. Both the colonization capabilities and the amount of suitable habitats on the coral fragments can be factors which influence the relative abundances of these taxa during colonization. 
There was a significant difference in copepodite abundance between different days. On day 2 and day 6 relative abundances of copepodites were highest and on day 14 they were at their lowest. Hicks (1992) found that copepodites are more easily suspended in the water column through passive erosion than adults. This could increase the amount of potential copepodite recruits in the water column, which could give them the ability to colonize coral fragments faster than adults. These results suggest that there are differences in dispersal between different age-classes, with copepodites showing on average higher dispersal rates than adults.

\section{Colonization mode}

No significant differences between the open and closed treatments were found. Almost all genera found in the open treatment were also recorded in the closed treatment. However, some differences in relative abundance of certain taxa were found between the two treatments.

These results indicate that most genera are able to colonize the coral fragments via the water-column. As coral fragments in the closed treatment were separated from the sediment by the walls and bottom of the core, copepods had to enter the water column and disperse at least $5 \mathrm{~cm}$ above the seafloor to reach the coral fragments. However, the possibility that some individuals reached the coral fragments by crawling over the cores should not be excluded. Hicks \& Coull (1983) suggested already that our traditional concept of benthic copepods as bound to the sediment must be re-assessed, and a number of studies have convincingly shown that both adult and juvenile harpacticoid copepods are regularly found in the water column (e.g. Palmer, 1988; Sun \& Fleeger, 1994; Atilla et al., 2003; Thistle \& Sedlacek, 2004). Harpacticoids can enter the water column either through passive erosion from the sediment or active entry into the water column (emergence) (Palmer, 1988). Our results however cannot confirm whether colonizers entered the water column due to active or passive processes.

On day 6, sediment-associated genera (i.e. Ameira, Amphiascus and Mesochra) had a higher relative abundance in the open treatment than in the closed treatment, which indicates that they colonize coral fragments mainly from the sediment. Although most sediment-associated genera do disperse via the water column, they can probably better resist the passive erosion and/or show less emergence behaviour than eurytopic or phytal species. Furthermore, eurytopic genera (mainly Ectinosoma) had a higher relative abundance in the closed treatment than in the open treatment, which indicates that Ectinosoma can easily colonize coral fragments through the water column.

The genera Karllangia Noodt, 1964 and Phyllopodopsyllus were only recorded in the open treatment. This indicates that these genera only colonized the coral fragments through the sediment, and that there was no dispersal via the water column. Thistle \& Sedlacek (2004) attempted to distinguish emerging- from non-emerging copepods using a set of morphological characteristics. They hypothesized that morphological characters associated with swimming should be characteristic for emerging copepods. Therefore, they used the morphology of pereiopods $2-4$, which are the primary locomotor appendages in copepods, to predict whether a species was an emerger or a non-emerger. In this study, Phyllopodopsyllus sp. was classified as non-emerger based on morphological characteristics, and the results support the finding of Thistle \& Sedlacek (2004) that members of this genus do not show emerging behaviour. The absence of Karllangia in the closed treatments also indicates that this is a non-emerging taxon. However, based on morphological characteristics used by Thistle \& Sedlacek (2004) this genus should be classified as an emerger. This finding indicates that the morphology-based classification of Thisle \& Sedlacek (2004) is probably not generally applicable. Therefore, experiments are needed to specifically assess the emerging behaviour of single species before any decisive conclusions can be drawn.

In conclusion, temporal succession patterns on dead coral fragments depend on the life-style and morphology of the colonizers. Phytal taxa show a fast colonization rate and high relative abundances during the initial colonization phase. Eurytopic and sediment-associated taxa show lower colonization rates and become the dominant group during the later colonization phase. Most taxa seem to have the ability to colonize coral fragments via the water column. However, colonization along the substrate surface can also be important, and this seems especially true for sediment-associated taxa, which showed lower colonization rates when migration through the sediment was hindered.

\section{ACKNDWLEDGEMENTS}

The authors wish to thank Dr M.S. Kyewalyanga, Dr N.S. Jiddawi and the staff from the Institute of Marine Sciences in Zanzibar (University of Dar es Salaam, Tanzania) for their logistic support. Special thanks go to B. Beuselinck, D. Van Gansbeke and A. Van Kenhove (Marine Biology Research Group, Ghent University, Belgium) for technical support. The following are greatly acknowledged for their financial support of the sampling campaign: Fund for Scientific Research (FWO-Flanders, Belgium), the King Leopold III Fund for Nature Exploration and Conservation and the Flemish Interuniversity Council (VLIR-UOS). Two anonymous referees are kindly thanked for critically reading the manuscript and providing constructive remarks.

\section{REFERENCES}

Adams A.J., Dahlgren C.P., Kellison G.T., Kendall M.S., Layman C.A., Ley J.A., Nagelkerken I. and Serafy J.E. (2006) Nursery function of tropical back-reef systems. Marine Ecology Progress Series 318, 287301.

Alongi D.M. (1989) The role of soft-bottom benthic communities in tropical mangrove and coral reef ecosystems. Aquatic Sciences 1, 243279.

Armenteros M., Creagh B. and González-Sansón G. (2009) Distribution patterns of the meiofauna in coral reefs from the NW shelf of Cuba. Revisita de Investigación Marina 30, 37-43.

Atilla N. and Fleeger J.W. (2000) Meiofaunal colonization of artificial substrates in an estuarine embayment. Marine Ecology 21, 69-83.

Atilla N., Wetzel M.A. and Fleeger J.W. (2003) Abundance and colonization potential of artificial hard substrate-associated meiofauna. Journal of Experimental Marine Biology and Ecology 287, 273-287.

Boxshall G.A. and Halsey S.H. (2004) An introduction to copepod diversity. London: The Ray Society, 966 pp. 
Chertoprud E.S., Azovsky A.I. and Sapozhnikov F.V. (2005) Colonization of azoic sediments of different grain-size composition by littoral Harpacticoida: Copepoda. Oceanology 45, 698-706.

Clarke K.R. and Gorley R.N. (2006) PRIMER v6: user manual/tutorial. Plymouth: PRIMER-E.

Coull B.C. (1977) Marine flora and fauna of the north-eastern United States. Copepoda: Harpacticoida. NOAA Technical Report NHFS Circular 399, 1-48.

Coull B.C. (1999) Role of meiofauna in estuarine soft-bottom habitats. Australian Journal of Ecology 24, 327-343.

De Troch M., Vandepitte L., Raes M., Suárez-Morales E. and Vincx M. (2005) A field colonization experiment with meiofauna and seagrass mimics: effect of time, distance and leaf surface area. Marine Biology $148,73-86$.

Gheerardyn H., De Troch M., Ndaro S.G.M., Raes M., Vincx M. and Vanreusel A. (2008) Community structure and microhabitat preferences of harpacticoid copepods in a tropical reef lagoon (Zanzibar Island, Tanzania). Journal of the Marine Biological Association of the United Kingdom 88, 747-758.

Giere O. (2009) Meiobenthology: the microscopic motile fauna of aquatic sediments. 2nd edition. Berlin: Springer-Verlag, $527 \mathrm{pp}$.

Gray J.S. (1985) Nitrogenous excretion by meiofauna from coral-reef sediments: Mecor 5. Marine Biology 89, 31-35.

Heip C., Vincx M. and Vranken G. (1985) The ecology of marine nematodes. Oceanography and Marine Biology: an Annual Review 23, 399489.

Hicks G.R.F. (1992) Tidal and diel fluctuations in abundance of meiobenthic copepods on an intertidal estuarine sandbank. Marine Ecology Progress Series 87, 15-21.

Hicks G.R.F. and Coull B.C. (1983) The ecology of marine meiobenthic harpacticoid copepods. Oceanography and Marine Biology: an Annual Review 21, 67-175.

Huys R., Gee J.M., Moore C.G. and Hamond R. (1996) Marine and brackish water harpacticoid copepods. Part 1: keys and notes for identification of the species. Synopses of the British fauna (New Series), 51, Volume VII. Shrewsbury, UK: Field Studies Council, $352 \mathrm{pp}$.

Huys R. (2009) Unresolved cases of type fixation, synonymy and homonymy in harpacticoid copepod nomenclature (Crustacea: Copepoda). Zootaxa 2183, 1-99.

Klumpp D.W., McKinnon A.D. and Mundy C.N. (1988) Motile cryptofauna of a coral reef: abundance distribution and trophic potential. Marine Ecology Progress Series 45, 95-108.

Kurdziel J.P. and Bell S.S. (1992) Emergence and dispersal of phytal dwelling copepods. Journal of Experimental Marine Biology and Ecology 163, 43-64.

Lang K. (1948) Monographie der Harpacticiden I \& II. Lund: Håkan Ohlssons Boktryckeri.

Lang K. (1965) Copepoda Harpacticoidea from the Californian Pacific coast. Kungliga Svenska Vetenskapsakademiens Handlingar 10, 1- 566.

Logan D., Townsend K.A., Townsend K. and Tibbetts I.R. (2008) Meiofauna sediment relations in leeward slope turf algae of Heron Island reef. Hydrobiologia 610, 269-276.

Montagna P.A. (1984) In situ measurement of meiobenthic grazing rates on sediment bacteria and edaphic diatoms. Marine Ecology Progress Series $18,119-130$.

Moriarty D.J.W., Pollard P.C., Alongi D.M., Wilkinson C.R. and Gray J.S. (1985) Bacterial productivity and trophic relationships with consumers on coral reefs (Mecor I). Proceedings of the 5 th International Coral Reef Symposium 3, 457-462.
Ndaro S.G.M. and Ólafsson E. (1999) Soft-bottom fauna with emphasis on nematode assemblage structure in a tropical intertidal lagoon in Zanzibar, eastern Africa: I. spatial variability. Hydrobiologia 405, $133-148$.

Noodt W. (1971) Ecology of the Copepoda. Smithsonian Contributions to Zoology 76, 97-102.

Ólafsson E., Ingólfsson A. and Steinarsdóttir M.B. (2001) Harpacticoid copepod communities of floating seaweed: controlling factors and implications for dispersal. Hydrobiologia 453/454, 189-200.

Palmer M.A. (1988) Dispersal of marine meiofauna: a review and conceptual model explaining passive transport and active emergence with implications for recruitment. Marine Ecology Progress Series 48, 8191.

Palmer M.A. and Gust G. (1985) Dispersal of meiofauna in a turbulent tidal creek. Journal of Marine Research 43, 179-210.

Raes M., De Troch M., Ndaro S.G.M., Muthumbi A., Guilini K. and Vanreusel A. (2007) The structuring role of microhabitat type in coral degradation zones: a case study with marine nematodes from Kenya and Zanzibar. Coral Reefs 26, 113-126.

Sun B. and Fleeger J.W. (1994) Field experiments on the colonization of meiofauna into sediment depressions. Marine Ecology Progress Series $110,167-175$.

Thistle D. and Sedlacek L. (2004) Emergent and non-emergent species of harpacticoid copepods can be recognized morphologically. Marine Ecology Progress Series 266, 195-200.

Walters K. and Bell S.S. (1994) Significance of copepod emergence of benthic, pelagic and phytal linkages in a subtidal seagrass bed. Marine Ecology Progress Series 108, 237-249.

and

Wells J.B.J. (2007) An annotated checklist and keys to the species of Copepoda Harpacticoida (Crustacea). Zootaxa 1568, 1-872.

\section{Correspondence should be addressed to:} M. Callens Aquatic Biology, K.U. Leuven-KULAK, E. Sabbelaan 53, 8500 Kortrijk, Belgium email: callens.martijn@hotmail.com

\section{APPENDIX}

List of identified families and genera.

Ameiridae Boeck, 1865

Ameira Boeck, 1865

Ameiropsis Sars, 1907

Psyllocamptus T. Scott, 1899

Sarsameira Wilson, 1924

Canthocamptidae Brady, 1880

Mesochra Boeck, 1865

Nannomesochra Gurney, 1932

Canuellidae Lang, 1944

Brianola Monard, 1927

Canuella Scott \& Scott, 1893

Cletodidae T. Scott, 1905

Genus 1

Dactylopusiidae Lang, 1963

Dactylopusia Norman, 1903 
Diarthrodes Thomson, 1883

Paradactylopodia Lang, 1944

Ectinosomatidae Sars, 1903

Ectinosoma Boeck, 1865

Halectinosoma Vervoort, 1962

Halophytophilus Brian, 1919

Microsetella Brady \& Robertson, 1873

Pseudobradya Sars, 1904

Sigmatidium Giesbrecht, 1881

Harpacticidae Dana, 1846

Harpacticus Milne-Edwards, 1840

Perissocope Brady, 1910

Zausodes Wilson, 1932

Laophontidae T. Scott, 1905

Esola Edwards, 1891

Heterolaophonte Lang, 1948

Laophonte Philippi, 1840

Paralaophonte Lang, 1948

Apistophonte Gheerardyn \& Fiers, 2006

Longipediidae Boeck, 1865

Longipedia Claus, 1862

Louriniidae Monard, 1927

Lourinia Wilson, 1924
Miraciidae Dana, 1846

Amphiascoides Nicholls, 1941

Amphiascus Sars, 1905

Bulbamphiascus Lang, 1944

Diosaccus Boeck, 1873

Robertgurneya Lang, 1948

Robertsonia Brady, 1880

Schizopera Sars, 1905

Stenhelia Boeck, 1865

Paramesochridae Lang, 1944

Apodopsyllus Huys, 2009

Emertonia Wilson, 1932

Parastenheliidae Lang, 1936

Karllangia Noodt, 1964

Parastenhelia Thompson \& Scott, 1903

Tegastidae Sars, 1904

Tegastes Norman, 1903

Tetragonicipitidae Lang, 1944

Diagoniceps Willey, 1930

Phyllopodopsyllus T. Scott, 1906

Tisbidae Stebbing, 1910

Scutellidium Claus, 1866

Tisbe Lilljeborg, 1853 